\title{
Context Awareness and Perceived Interactivity in Multimedia Computing
}

\author{
$\mathrm{Xiao}_{\text {Dong }}{ }^{1}$ and Pei-Luen Patrick Rau ${ }^{2}$ \\ ${ }^{1}$ Industrial \& System Engineering Department, University of Minneosta, \\ Minnesota, USA \\ dongx080@umn. edu \\ ${ }^{2}$ Industrial Engineering Department, Tsinghua University, \\ Beijing, P.R. China \\ rpl@tsinghua.edu.cn
}

\begin{abstract}
Context awareness and perceived interactivity are two factors that might benefit mobile multimedia computing. This research takes mobile TV advertisements as a scenario and verifies the impacts of perceived interactivity and its interaction with context awareness. Seventy-two participants were recruited and an experiment was conducted in order to identify those impacts. The main findings indicated the following: (1) the effect of high perceived interactivity advertisement is significantly better than the effect of low perceived interactivity advertisement; (2) the interaction of context awareness and perceived interactivity has a significant influence on the effect of mobile TV advertising.
\end{abstract}

Keywords: Context awareness, perceived interactivity, mobile TV advertising.

\section{Introduction}

Mobile multimedia has emerged as the hottest growth area in wireless services. It brings a host of new features and functions into the wireless market, providing advanced forms of communication, entertainment and productivity [1]. Mobile operators are investing considerably in broadcasting mobile TV with fully fledged services in various countries throughout Asia as well as other large scale trials around the world [2]. Although mobile advertising and TV advertising have been studied for many years, few researchers have extended their studies to include TV advertising on the platform of mobile devices. With the development of network and hardware capacity, mobile devices can be used to watch TV programs.

The purpose of this study was to identify user perception and response to mobile multimedia services. The result can be a guidance of advertisement designers and a base for further studies.

\section{Literature Review}

\subsection{Mobile Multimedia}

Mobile TV fulfills the growing need of entertaining and staying informed on the move. Mobile TV builds on established consumer behavior: end-users are familiar 
with the concept of television and, with the continued need for mobility, the benefits of this new medium are clear. Mobile TV is enhanced by the element of interactivity, which adds value to the user experience and makes it a richer entertainment option.

\subsection{Mobile Advertising}

Compared with traditional advertising media, mobile advertising can promote sales of goods and services, create brand images and product awareness (branding), disseminate information using a personally relevant and context-aware approach, support direct business transactions and encourage customer interaction $[3,4]$.

In recent years, mobile advertising has been enhanced by the processing capability of handheld devices and the development of networks. Consequently, some innovative advertising methods are found in everyday life. For instance, mobile games and MMS advertising have emerged as creative advertisement venues. However, mobile advertisers must be very careful not to risk privacy issues and exhaust customer tolerance. We are of the opinion that it is the users and not the media designers or the market that are the ultimate determinants of effectiveness.

\subsection{Context}

The context is frequently determined by user location $[5,6]$. Hence, depiction and association of user location is pivotal to a context-sensitive advertising system. Potential application fields can be found in areas such as travel information, shopping, entertainment, event information and different mobile professions [5]. Another reason for the importance of location is that it is easier to identify and measure compared with other context components. It can be measured with different positioning systems, such as embedded GPS modules, mobile phones which can be located by the telecom operator of a network, or service points utilizing WLAN, Bluetooth, or infrared technologies.

\subsection{Perceived Interactivity}

Interactivity is generally believed to be a multi-dimensional construct $[7,8,9,10]$, but there is no general consensus regarding the nature and the content of the dimensions. Based on constructs identified in internet studies and analysis of the characteristics of mobile communication, a model of interactivity for mobile advertisements was constructed by Gao et al. [11], comprising user control, direction of communication, synchronicity, connectedness, playfulness, and interpersonal communication. They also stated that different mobile advertising tools might differ in these dimensions due to the different communication style each tool has. For example, message push-ads might allow less user control, but an included reply option will give customers a convenient channel to respond; mobile banners are less intrusive compared with pushads, but they might be ignored or assumed to be only decorative images.

User control is conceptualized as the degree of user intervention that is required to operate the system [12]. Dholakia et al. refer to user control as the extent to which an individual can choose the content, timing and sequence of a communication to change his/her viewing experience [13]. It is taken as the core component of interactivity by some researchers [10,14]. Two constructs identified by Steuer [10], range and 
mapping, actually describe two aspects of control. The former refers to the number of options the environment provides the user to modify the task flow and the environment, and the latter refers to the extent to which the controls and manipulations in a computer-mediated environment are similar to controls and manipulations in the real word. This paper manipulates interactivity by adding different user controls to the advertisement.

\section{Hypotheses and Methodology}

\subsection{Hypotheses}

Hypothesis 1: High perceived interactivity advertisements will have better advertising effectiveness(better memory, better attitudes towards the ads and brand, higher purchase intention) than low perceived interactivity advertisements.

For message advertising, user control options are important. Control choice/range and mapping have been traditionally considered as fundamental constructs of interactivity $[15,10]$. Users can respond by replying to the message directly, call back with a provided telephone number, or visit another source linked in the message. Users also want the control and manipulation in computer-mediated environments to be similar to those in the real world. The more a user can control the options provided, the more interactive the customer perceives the advertisement to be. The more similar the mediated environment is to the real world, the more interactive the customer perceives the advertisement to be.

Studies on Internet advertising interactivity have found that there is a strong correlation between perceived interactivity and advertising effectiveness in terms of attitude towards brand, attitude towards ads, and purchase intention [16,17,18]. Previous study also suggested that higher interactivity helps the customer experience "flow" during the interaction [19] and the consequences of the "flow" experience are increased learning and perceived behavioral control. Therefore it was hypothesized that high perceived interactivity has a positive influence on advertising effectiveness.

Hypothesis 2: The interaction between interactivity and context-awareness will have an influence on mobile advertising effectiveness.

While context-awareness ads give users higher involvement and make the ads more relevant, interactivity provides the customer a chance to communicate with the company, to search for further information or to disseminate information to others conveniently and quickly. As Kannan et al. [20] have already pointed out, it is critical to provide the customer a chance to respond at the point of purchase or usage immediately when sending context-aware advertisements. Immediately redeemable m-coupons, callback numbers, or simply a message requiring a reply from the customer are hypothesized as most likely to exert influence when sent in a contextaware manner compared to when sent in a context-irrelevant manner. Context awareness and interactivity are hypothesized to have an interaction effect on advertising effectiveness. 


\subsection{Experiment}

Participants. Seventy-two participants (36 female and 36 male) from Universities in Beijing voluntarily took part in the experiment. They were randomly assigned to six groups with the combination of two-level context awareness and three-level perceived interactivity. The participants were all undergraduate and graduate students with no prior knowledge about the tasks to be performed during the experiment. The participants' ages ranged from 20 to 36 years (mean=24, S.D. $=2.26$ ) and 55\% of the participants had used mobile phones for more than five years. In addition, $98 \%$ of the participants had previously received SMS advertisements, and 32\% of the participants had received MMS advertisements. $90 \%$ of the participants had more than five years of Internet experience, while $32 \%$ of the participants had experience connecting to the Internet via mobile devices.

Experimental design and variables. Independent variables are perceived interactivity and its interaction with context awareness. Dependent variables were advertising effectiveness which consisting of memory of the advertisement, attitude towards the advertisement and brand, and purchase intention. Memory was measured by a free recall and recognition test. The ads attitude [8], brand attitude [21], user involvement [22] and purchase intention was measured using scales from other researches.

Procedures. Each participant was tested individually. They were asked to complete a demographic and technology (internet, mobile services and TV advertisements) usage questionnaire. Then the participants were given an introduction to the experiment's procedure and their tasks. A practice task was provided to let the participants view sample mobile TV advertisements and make sure they knew how to use the experiment devices (PDA-ASUS A620, KONKA TPC880). During the experiment, all participants visited five different scenarios (mall, bookstore, cell phone market, McDonald's, and the IE building at Tsinghua University) with a predefined sequence. In each scenario, they did two information seeking tasks and viewed mobile TV advertisements on experiment devices after each task. According to different groups, context awareness and perceived interactivity features were embedded into mobile TV advertisements.

Upon completion of all tasks, a free-recall test and an advertisement recognition test were given; the participants were not informed prior to the task that these tests would be applied. Then participants were asked to finish a post-test questionnaire, which measured the user's attitude towards the ads, brand attitude, perceived interactivity, as well as purchase intention.

\section{Results and Discussions}

In this section we present the reliability of each measure and the results of test hypotheses one and two. The internal consistencies for the questionnaire responses, using Cronbach's a, were 0.95 for the advertisement attitude questionnaire, 0.95 for the brand attitude questionnaire and 0.87 for the involvement with the advertisement questionnaire, and 0.78 for the perceived interactivity questionnaire. 


\subsection{The Effect of Perceived Interactivity on Advertisement}

It was hypothesized in this study that high perceived interactivity advertisements would have better advertising effectiveness than low perceived interactivity advertisements. High range and high mapping are two different kinds of high level perceived interactivity. They are compared with low perceived interactivity separately to identify whether this hypothesis is true. After the experiment, the data showed that there were significant differences between exposure time to mobile TV advertisements in each group. This factor was used as a covariate in the ANCOVA process.

The results can be found in Tables 1 and 2 .

Table 1. Data for Testing Hypothesis Three (High rangexLow interactivity)

\begin{tabular}{llllll}
\hline \multicolumn{7}{l}{ Perceived interactivity } \\
\hline High range & \multicolumn{2}{l}{ Low interactivity } & P value \\
& Mean & SD & Mean & SD & \\
\hline Ad free recall & 2.93 & 1.73 & 1.77 & 1.05 & $0.003^{*}$ \\
Ad recognition & 7.33 & 1.88 & 6.13 & 2.25 & $0.04^{*}$ \\
Ad attitude & 4.80 & 0.52 & 4.24 & 0.53 & $0.00^{*}$ \\
Brand attitude & 4.87 & 0.53 & 4.28 & 0.41 & $0.00^{*}$ \\
Purchase intention & 4.69 & 0.69 & 4.08 & 0.49 & $0.00^{*}$ \\
\hline
\end{tabular}

Table 2. Data for Testing Hypothesis Three (High mapping $\times$ Low interactivity)

\begin{tabular}{llllll}
\hline \multicolumn{7}{l}{ Perceived interactivity } \\
\hline Variable & Mean & SD & Mean & SD & \\
\hline Ad free recall & 2.82 & 1.46 & 1.77 & 1.05 & $0.006^{*}$ \\
Ad recognition & 7.46 & 2.43 & 6.13 & 2.25 & $0.02^{*}$ \\
Ad attitude & 4.60 & 0.65 & 4.24 & 0.53 & $0.02^{*}$ \\
Brand attitude & 4.62 & 0.57 & 4.28 & 0.41 & $0.01^{*}$ \\
Purchase intention & 4.35 & 0.70 & 4.08 & 0.49 & 0.10 \\
\hline
\end{tabular}

From these results we can see that hypothesis one is supported. High perceived interactivity advertisements will have better advertising effectiveness than low perceived interactivity advertisements. This was consistent with past studies. Cho and Leckenby [16] measured participants' intention to interact with a target (banner) ad and found positive relations (correlation coefficients ranging between .30 and .75) between intention to interact with the ad and attitudes toward the ad, attitudes toward the brand, and purchase intention. Yoo and Stout [18] also achieved similar results. McMillan and Hwang's [17] study demonstrated that interactivity and involvement 
with the subject of a site were two possible predictors of positive attitude towards the Web site, and perceived interactivity accounted for more of the variance in attitude than did involvement. Analysis of relationships among the variables in the study suggested that the control sub-dimension of perceived interactivity had the strongest correlation with attitude toward the Web site.

\subsection{Joint Effect of Context-Aware and Perceived Interactivity}

It was hypothesized in this study that the interaction between interactivity and context awareness influences mobile advertising effectiveness. As mentioned above, we also included exposure time to mobile TV advertisement in each group as the covariate in the ANCOVA test. The results showed that the interaction between perceived interactivity and context awareness significantly influenced the subject's attitude towards mobile TV advertisements $(\mathrm{F}=4.183, \mathrm{p}=0.019)$, their attitude towards brands $(\mathrm{F}=5.011, \mathrm{p}=0.009)$, and their purchase intention $(\mathrm{F}=7.732, \mathrm{p}=0.001)$. Although the interaction between context awareness and perceived interactivity have no significant influence on advertisement free recall and advertisement recognition, the $\mathrm{p}$ value is quite close to the significant level $\mathrm{p}=0.05(\mathrm{~F}=2.22, \mathrm{p}=0.117$ for free recall; $\mathrm{F}=2.793, \mathrm{p}=0.068$ for recognition $)$.

Table 3. The Effect of Interactivity under the Context-aware Condition

\begin{tabular}{lllllllll}
\hline & \multicolumn{4}{l}{ Perceived interactivity } & & & F value & P value \\
\hline & High range & \multicolumn{4}{l}{ High mapping } & \multicolumn{2}{l}{ Low interactivity } & \\
Variable & Mean & SD & Mean & SD & Mean & SD & & \\
\hline Ad free recall & 3.47 & 2.07 & 3.31 & 1.68 & 1.55 & 0.87 & 5.16 & 0.01 \\
Ad recognition & 7.92 & 1.51 & 8.50 & 2.02 & 5.75 & 2.42 & 6.20 & 0.01 \\
Ad attitude & 5.14 & 0.40 & 4.68 & 0.72 & 4.13 & 0.52 & 9.72 & 0.00 \\
Brand attitude & 5.20 & 0.38 & 4.64 & 0.66 & 4.19 & 0.43 & 11.86 & 0.00 \\
Purchase intention & 5.13 & 0.52 & 4.28 & 0.83 & 3.88 & 0.46 & 12.45 & 0.00 \\
\hline
\end{tabular}

Table 4. The Effect of Interactivity under the Context-irrelevant Condition

\begin{tabular}{lllllllll}
\hline & \multicolumn{4}{l}{ Perceived interactivity } & & & F value & P value \\
\hline & High range & \multicolumn{4}{l}{ High mapping } & \multicolumn{3}{l}{ Low interactivity } \\
Variable & Mean & SD & Mean & SD & Mean & SD & & \\
\hline Ad free recall & 2.39 & 1.15 & 2.33 & 1.03 & 1.99 & 1.20 & 0.43 & 0.65 \\
Ad recognition & 6.75 & 2.09 & 6.42 & 2.43 & 6.50 & 2.11 & 0.07 & 0.93 \\
Ad attitude & 4.46 & 0.40 & 4.52 & 0.58 & 4.35 & 0.54 & 0.34 & 0.71 \\
Brand attitude & 4.54 & 0.44 & 4.61 & 0.49 & 4.37 & 0.39 & 0.94 & 0.40 \\
Purchase intention & 4.26 & 0.57 & 4.41 & 0.57 & 4.27 & 0.46 & 0.30 & 0.75 \\
\hline
\end{tabular}

After examining the effect of interactivity in different context conditions (Tables 3 and 4), we found that when mobile advertisements are distributed in a context-aware manner, the interactivity of ads has a positive influence on the advertising effectiveness in terms of advertisement memory, advertisement attitude, brand attitude, and purchase intention. However, when mobile ads are distributed in a context-irrelevant way, the interactivity of advertisements has no significant influence on advertisement memory, 
advertisement attitude, brand attitude and purchase intention. This finding is partially contradictory with previous literatures in Internet advertising, where it is generally agreed that perceived interactivity has positive influences on advertising effectiveness $[16,17,18]$. The main reason for the lack of significant effects of interactivity in the context-irrelevant situation may be the lower message involvement in the contextirrelevant condition. First, low involvement leads to a lower information processing level, which may cause the subject to neglect the interaction options of the advertisement or even the advertisement itself. Second, lower involvement with the advertisement content also results in lower motivation to respond to the ad [23]. The lower motivation to respond makes it less critical to provide interaction options, since they do not seek interaction options from the beginning. When the same advertisements were sent in a context-aware manner, however, the effects of the interactivity of mobile advertisements on advertising effectiveness became significant, as expected in hypotheses one.

The results in Tables 5, 6 and 7 show that when the interactivity of mobile ads is low, to send them in a context-aware manner could result in even worse advertising

Table 5. The Effect of Context Awareness to High Range Advertisements

\begin{tabular}{|c|c|c|c|c|c|c|}
\hline \multirow[b]{3}{*}{ Variable } & \multicolumn{4}{|c|}{ Context awareness } & \multirow[t]{3}{*}{ F value } & \multirow[t]{3}{*}{$\mathrm{P}$ value } \\
\hline & \multicolumn{2}{|c|}{ Location relevant } & \multicolumn{2}{|c|}{ Location irrelevant } & & \\
\hline & Mean & $\mathrm{SD}$ & Mean & SD & & \\
\hline Ad free recall & 3.47 & 2.07 & 2.39 & 1.15 & 2.46 & 0.13 \\
\hline Ad recognition & 7.92 & 1.51 & 6.75 & 2.09 & 2.46 & 0.13 \\
\hline Ad attitude & 5.14 & 0.40 & 4.46 & 0.40 & 17.55 & 0.00 \\
\hline Brand attitude & 5.20 & 0.38 & 4.54 & 0.44 & 15.50 & 0.00 \\
\hline Purchase intention & 5.13 & 0.52 & 4.26 & 0.57 & 15.13 & 0.00 \\
\hline
\end{tabular}

Table 6. The Effect of Context Awareness to High Mapping Advertisements

\begin{tabular}{|c|c|c|c|c|c|c|}
\hline \multirow[b]{3}{*}{ Variable } & \multicolumn{4}{|c|}{ Context awareness } & \multirow[t]{3}{*}{ F value } & \multirow[t]{3}{*}{$\mathrm{P}$ value } \\
\hline & \multicolumn{2}{|c|}{ Location relevant } & \multicolumn{2}{|c|}{ Location irrelevant } & & \\
\hline & Mean & $\mathrm{SD}$ & Mean & $\mathrm{SD}$ & & \\
\hline Ad free recall & 3.31 & 1.68 & 2.33 & 1.03 & 2.97 & 0.10 \\
\hline Ad recognition & 8.50 & 2.02 & 6.42 & 2.43 & 5.21 & 0.03 \\
\hline Ad attitude & 4.68 & 0.72 & 4.52 & 0.58 & 0.37 & 0.55 \\
\hline Brand attitude & 4.64 & 0.66 & 4.61 & 0.49 & 0.02 & 0.90 \\
\hline Purchase intention & 4.28 & 0.83 & 4.41 & 0.57 & 0.19 & 0.67 \\
\hline
\end{tabular}

Table 7. The Effect of Context Awareness to Low Interactivity Advertisements

\begin{tabular}{lllllll}
\hline & \multicolumn{3}{c}{ Context awareness } & F value & P value \\
\hline & Location relevant & \multicolumn{2}{l}{ Location irrelevant } \\
Variable & Mean & SD & Mean & SD & & \\
\hline Ad free recall & 1.55 & 0.87 & 1.99 & 1.20 & 1.06 & 0.31 \\
Ad recognition & 5.75 & 2.42 & 6.50 & 2.11 & 0.66 & 0.43 \\
Ad attitude & 4.13 & 0.52 & 4.35 & 0.54 & 0.98 & 0.33 \\
Brand attitude & 4.19 & 0.43 & 4.37 & 0.39 & 1.05 & 0.32 \\
Purchase intention & 3.88 & 0.46 & 4.27 & 0.46 & 4.14 & 0.05 \\
\hline
\end{tabular}


effectiveness than to send them in a context-irrelevant manner, in terms of memory, advertisement attitude, brand attitude and purchase intention. However, when the interactivity of mobile ads is high, it is better to send them in a context-aware manner so as to promote the advertising effectiveness in terms of memory, advertisement attitude, brand attitude and purchase intention. In this study, we also found that the high range effect was greater than the high mapping effect as the indicator of perceived interactivity.

The finding that context awareness with low interactivity ads has a negative influence on advertisement effectiveness is surprising. We propose two reasons to address this. (1) Location-based services and advertisements should be provided with great care so as not to invade users' privacy, since handsets are very personal devices. The low interactivity ads only "broadcast" information about products and services. It is possible that the feeling of being invaded by such ads might become even stronger when users detect that their cell phones are being spammed just because they happen to walk past a particular store. (2) Mobile TV advertisement is characterized by its rich media features. Context awareness may influence advertisement effectiveness through other factors, such as interactivity. But further study is required to identify their relationship.

\section{Conclusion and Future Study}

The effect of perceived interactivity is clear in this study. High perceived interactivity advertisements have better advertising effectiveness than low perceived interactivity advertisements. This finding is consistent with former research on internet and mobile message advertisement. One guideline of perceived interactivity based on this research ought to be formed to give mobile TV advertisement business market instructions.

The effects of context awareness on mobile TV advertising effectiveness take place according to different levels of interactivity. With high interactive advertisements, contextual advertising information does increase user response effectively and results in a more accepting attitude. Therefore, when the goal of a mobile advertising campaign is to generate responses, the context in which the response options are given to the users are of importance and must be taken into consideration by the mobile marketer. However, with "broadcasting" advertisements, the user's attitude towards the brand and the consequent purchase intention were impaired by context aware advertisements rather than improved. This interaction style is needed to be thoroughly studied by future studies.

\section{References}

1. Robert, W.S.: Mobile multimedia goes Net-centric. Electronic Engineering Times. Manhasset: Mar 5(1156), 78-79 (2001)

2. Kenton, O., April, S.M., Alex, V.: Consuming Video on Mobile Devices. In: Proc. CHI 2007, pp. 857-866. ACM Press, New York (2007) 
3. Dickinger, A., Haghirian, P., Murphy, J., Scharl, A.: An Investigation and Conceptual Model of SMS Marketing. In: Proc. 37th Hawaii International Conference on System Sciences 2004, p. 10031.2. IEEE Computer Society Press, Los Alamitos (2004)

4. Yunos, H., Gao, J.: Wireless Advertising's Challenges and Opportunities. Computer 36, 30-37 (2003)

5. Kaasinen, E.: User needs for location-aware mobile services. Personal and Ubiquitous Computing 7, 70-79 (2003)

6. Younghee, J., Per, P., Jan, B.: DeDe: Design and Evaluation of a Context-Enhanced Mobile Messaging System. In: Proc. of CHI 2005. ACM Press, New York (2005)

7. $\mathrm{Wu}, \mathrm{G} .:$ Perceived Interactivity and Attitude Toward Web Sites. In: Proc. Conference of the American Academy of Advertising 1999. American Academy of Advertising (1999)

8. Ha, L., James, E.: Interactivity Reexamined: An Analysis of Business Web Sites. In: Proc. Conference of the American Academy of Advertising (1998)

9. Liu, P., Shrum, L.: What is interactivity and is it always such a good thing? Implications of definition, person, and situation for the influence of interactivity on advertising effectiveness. Journal of Advertising 31, 53-64 (2002)

10. Steuer, J.: Defining Virtual Reality: Dimensions Determining Telepresence. Journal of Communication 42(4), 73-93 (1992)

11. Gao, Q., Rau, P.L.P., Salvendy, G.: Measuring perceived interactivity of mobile advertisements. Behavior \& Information Technology (2006)

12. Van der Heijden, H.: Ubiquitous computing, user control, and user performance: conceptual model and preliminary experimental design. In: Proc. Tenth Research Symposium on Emerging Electronic Markets, pp. 107-112 (2003)

13. Dholakia, R., Zhao, M., Dholakia, N., Fortin, D.: Interactivity and Revisits to Websites: A Theoretical Framework, http: / / ritim.cba.uri.edu/wp/

14. Bezjian-Avery, A., Calder, B., Lacobucci, D.: New Media Interactive Advertising vs.Traditional Advertising. Journal of Advertising Research 38(94), $23-32$ (1998)

15. Coyle, J., Thorson, E.: The Effects of Progressive Levels of Interactivity and Vivideness in Web Marketing Sites. Journal of Advertising 30(3), 65-78 (2001)

16. Cho, C.-H., Leckenby, J.: Interactivity as a measure of advertising effectiveness: Antecedents and Consequences of Interactivity in Web Advertising. In: Proc. Conference of the American Academy of Advertising (1999)

17. McMillan, S., Hwang, J.S.: Measures of Perceived Interactivity: An Exploration of Communication, User Control, and Time in Shaping Perceptions of Interactivity. Journal of Advertising 31(3), 41-54 (2002)

18. Yoo, C.Y., Stout, P.: Factors Affecting User's Interactivity with the Web site and the Consequences of User's Interactivity. In: Proc. Conference of the American Academy of Advertising (2001)

19. Hoffman, D., Novak, T.: Marketing in Hypermedia Computer-Mediated Environments: Conceptual Foundations. Journal of Marketing 60(3), 50-68 (1995)

20. Kannan, P., Chang, A., Whinston, A.: Wireless commerce: marketing issues and possibilities. In: Proc. International Conference on System Science 2001. IEEE Computer Society Press, Los Alamitos (2001)

21. Li, H., Bukovac, J.L.: Cognitive Impact of Banner Ad Characteristics: An Experimental Stud. Journalism and Mass Communication Quarterly 76(2), 341-353 (1999)

22. Norris, C.E., Colman, A.M.: Context effects on recall and recognition of magazine advertisements. Journal of Advertising 21(3), 37-46 (1992)

23. Petty, R.E., Cacioppo, J.T.: Attitudes and Persuasion: Classic and Contemporary Approaches. Westview Press (1981) 